\title{
Transformational Processes in Organizational Life: Symbolic Imprinting and Symbolic Triggers
}

\author{
Dina Aslamazishvili \\ PhD Candidate of Philosophical Sciences, Professor, Scientific Group Member, Georgian American University, \\ Business School, Tbilisi, Georgia,dinaaslamazishvili@gau.ge
}

\begin{abstract}
Organizational life is multi-focused symbolic reality today, new and existing employees learn, transfer and transform in working experience. Managerial actions give both real and symbolic results. Symbolic contexts, like influence, commitment, shared values, mission clearance in project teams and others, create challenges. The paper discusses symbolic imprinting and symbolic triggers in organizational life, and shares the first cut results of the study through the metaphoric mechanics among business school students with fresh working experience. Symbolic imprinting constitutes stamping in memory some transferring values and meaning interpretations, and symbolic triggers are the external environment signs and images, which make imprints work out in specific thinking, behavioral, and communication mechanisms. Transformational processes - learning, growing, development, - are realized within the symbolic context. Symbolic imprints and triggers transfer specific concept of the organizational life, freeing up the meanings and important orientations for 'homo symbolicus'.
\end{abstract}

KEYWORDS: symbolic management, transformational processes, organizational life, organizational symbolism, symbolic imprints, symbolic triggers

\author{
"The snake which cannot cast its skin has to die. \\ As well the minds which are prevented from \\ changing their opinions; they cease to be mind. \\ Those who have a 'why' to live, can bear with almost any 'how'.
}

F. Nietzsche

\section{Introduction}

Transformation is the foundation of the Universe and human existence. Milton Erickson within the five coaching principles underlined that 'change is inevitable' (Atkinson and Chois 2007). Everything changes, nothing exists or continues without change. It concerns physiology, Earth, seasons, biology, society and human spirit. Merilyn Atkinson and Rae T. Chois in the "Inner Dynamics of Coaching" continue their speculations around the symbol of Human - letter $\mathrm{H}$, which looks like human body, and is a symbol of the human nature building (Ibid.). Organizational life is created around human, it is a symbolic system, which is regulated by the human factor. In organizational life this symbol $-\mathrm{H}-$ as founded on the ground and appealing to something in the air, as rooting in the basis and growing for development, transcending the levels of existence, - stands for the organizational life transformation processes. Transformation differs from transition in the context and content merge, so transformation is possible only through symbolic.

\section{Symbol and Transformational Processes in Organizational Life}

Symbol is an intuitive spiritual inception displayed by means of signs, images, and metaphors that give shape to symbolic sphere. The symbolic sphere consists of the three areas - psychological (image), semantic (metaphor), and communicative (sign). In all these areas images, metaphors and signs exist as simulacra of the original symbol's meaning. Susan Langer (2000) observing the symbolic, underlines that symbols present not the objects but are transferring specific concept on those objects . So, symbols and symbolic in organization transfer the concept and context on the common objects, operations and actions. Symbol is the merge of the context and the content. Organizational life is created and based on symbolic relations. Semantic, communicative and psychological areas unfold the code law of 
organization today. Jean Baudrillard (1994). underlines that symbolic is not a meaning, not a state, not a category neither structure, it's an act of exchange and social relation setting the end of reality, resolving in itself reality, and opposition of reality and imaginary. Symbol has transformational energy, energy to transform the reality and the imaginary. Instead of transactional - just exchange of meanings, symbol creates transformational space, - connecting, merging and changing the meanings.

Humans surround their activity by many rituals and attach meanings to these activities and rituals as well. When people get together they 'organize' these activities, meanings and rituals in such a way that they constitute tradition, and in some sense with the mental field intervention as well culture (something defining behaviour opposite to nature). These surroundings have symbolic nature, and brightly are deployed in organizational life, where group of people within the specific structure define specific purpose. The 'human' component creates additional complexity for the system managers need to plan, organize, lead and control in. This complexity is resolved in the transformational processes, like new employee orientation programs, or learning and development cycles, or gamification in human resources management, and others. Any action, rule or solution creates transformational energy, and human - letter $\mathrm{H}$ as symbol, is founded on the ground of the organization, and appeals to transcend it in the growing potential. The ground symbolically is presented by the symbolic imprinting, and the growing transcendence - by the symbolic triggers.

\section{Symbolic Imprinting and Symbolic Triggers}

Imprinting is mostly studied in animals, less in human psychology. In its genesis it means 'stamped in' impression, tactile, visual or sound memory. It is like the selective fixed information in memory. All people have periods when their memory is sensitive to imprinting, so some environmental events can be stamped in, and influence decision, behavior and even values choice in the future. Symbolic context of organizational life (interactions, communication, relationships, decisions, job satisfaction etc.) creates the situation for human sensibility, as it is the situation of suspense (border situation). Mircea Eliade (1991) specified that rituals open the suspense situation of a humankind; it is a situation where human realizes the place in the world. Symbols' function in Eliade's interpretation, is to open the whole reality, other means are not able to do. Karen Svasian (2000) states that there is no symbol itself in any of its forms; its being is in metamorphose, is forms transform. So, symbolic situation is a situation of transformation, and symbolic imprinting gets its place in these situations in organization. Social imprinting is presented in the number of imprints among people, like basic principles, values, stereotypes, which in their turn define the attitudes towards leadership, discipline, ethical issues etc. Symbolic imprinting means stamping in memory some transferring values and meaning interpretations, which define the actions and behaviors. For example, in organization symbolic imprints can be values important for the group of people and successes they experience together. The symbolic imprints are deployed in meanings and understanding employees hold about organizational goals, priorities, can be transferred into job satisfaction, attitudes and decisions.

Symbolic triggers are the factors of the external environment which start specific behavioural mechanisms, usually transcendental, exceeding the limitations for growing. In some sense basic behavioural imprinting is displayed in the reactions on triggers in organization. In the specific situation people release these imprints in their understanding and interpretation, which in its way lead to the specific behaviour. Marshall Goldsmith (2015) in his view on triggers in life and workplace underline the importance of self-awareness in making decisions and choosing the style of behaviour. Struggling with triggers is especially difficult what they have symbolic context and are based on the symbolic imprints, not changeable over time.

Symbolic imprinting with the transformational energy gives the growing symbolic triggers, something which can make a person to change the basic reactions, and to activate a mechanism of a total different quality. Gregory Bateson (1972) describes the learning levels from 0 to IV. Level 0 is not transformational, it is changing nothing, keeping same patterns even if they are ineffective, just keeping doing the same. In pure meaning of the word 'learning' 0 level is like not learning, it is more repeating the same pattern. Level I when already change can start, it is correction and step-by-step modifications and adaptation. Level II learning is about jumping changes, like jumping from one system to another, 
radically different; for example, change of policy, direction, 'frame'. Level III is evolutionary change, some important improvements within the existing context or pattern, development, but immanent changes, becoming the new pattern, paradigm. Learning IV is revolution, going outside of the pattern, of the system, radical context change, quality change in the mindset, new vision and view of the world, you and content. Interpreting the Bateson's levels within symbolic triggers and imprinting, Level 0 learning is realization of imprinted patters with no change. People learn the patterns in pre-awareness way, so they learn something in organization, and only then in Level I can become more aware, realize the meaning or need of this rule or behavior. Level IV learning is the transformational energy of symbolic triggers, making people transcend to another context, change the mindset, and develop mindfulness in organizational life [see Figure 1].

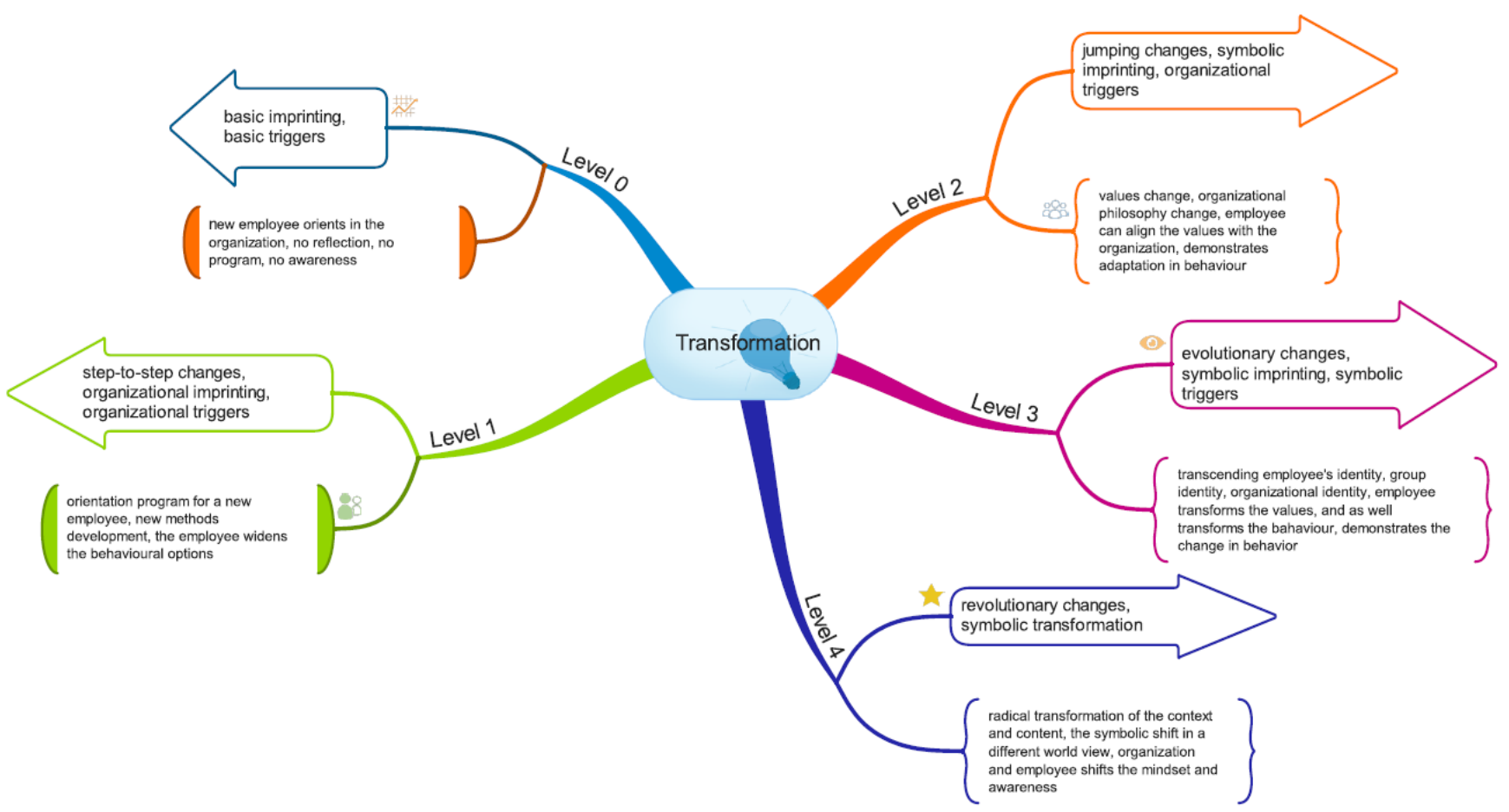

Figure 1. Symbolic Imprinting and Symbolic Triggers in Connection with Bateson's Leaning Levels

\section{Study of Transformational Processes Symbolic Imprinting and Symbolic Triggers}

Symbolic activities should be studied through symbolic mechanisms. For this study it was chosen metaphor, specifically fairy-tale. Respondents (students with the first employment experience) were asked to recall their first experience when they joined the company work for now, or worked for before. The respondents additionally were asked to imagine if they would describe this experience in the fairytale format and answer several questions [see Table 1].

The answers varied in their imagination and context interpretation, as well reflected the nature of the imprinting and triggers experience respondents have or had in their orientation period in the workplace. In the first question about the hero, about $80 \%$ of respondents underlined the courage and at the same time freight of the main hero, as well as openness and readiness for learning. About $20 \%$ chose as the main hero a strong figure (associated with the Leader in the organization), e.g. Father or Beast (from 'Beauty and the Beast' tale), describing the hero as strong, rich, successful and protecting.

The second question included other characters of the fairy-tale story with their behavioural patterns and styles description. Respondents demonstrated the reverse in this question, i.e. those who have as the main hero someone not confident enough yet, choose as other characters confident and ready-to-help people, experienced, educated and calm. If the others were described as 'cruel', the main 
hero is looking for those who are 'helpful and supportive' (only about $10 \%$ of respondents). In one example, the hero and other heroes are not in a reverse, both are confident, calm and ready.

The third question was dedicated to the events in the beginning. Most of the answers metaphorically represent some problem, new issue to deal with, something not known or not lived through experience, e.g. 'the world is new', 'struggle, separation from family', 'curse', or something bad happened, 'the main hero's sister was taken to the deep forest by Hydra', etc. In all the beginnings there was a need of both hero and other characters who are more experienced, to participate in the saving campaign.

Question four had the most important meaning for the research, to see the reasons people find their transformations based on, like the symbolic transformational energy, more level of symbolic imprinting and symbolic triggers. Respondents include in this metaphoric challenge someone or something not met before in the story, e.g. family, new person, hero's partner, people like her, and others. About $20 \%$ of respondents underline that 'life' itself or situation itself made the hero to transform.

In the question five the respondents' endings vary. The hero and the partner defeated the 'monster and saved the girl', they solved the problem, and came out as real heroes. The hero is aware of who she is and what she wants, come back to real self and get the partner who accepts this real self. The hero overcame the moral obstacles. About 30\% offer 'happy end', and 10\% suggests a negative situation in the end, which strengthens the hero in what $\mathrm{s} / \mathrm{he}$ is.

Questions six and seven were related to the morale and values of the fairy-tale stories. These two mostly copied each other, so the answers were in parallel, demonstrating the values and attitudes important for the respondents in the workplace, e.g. strength, unity, to be oneself and to accept oneself, follow your goals, stability, calmness, kindness, to become not a hero, but the other character in the fairy-tale story (to reverse).

Table 1. Questions of the Study

1. Who is the main hero of your fairy-tale story? Describe the main hero (traits, behaviours, style)

2. Who are the other heroes in your fairy-tale story? Describe their traits, behaviours, style.

3. What happened with the main hero in the beginning?

4. What made the main hero to transform him/her or his/her style?

5. What is the end of your fairy-tale story?

6. What is the morale of your fairy-tale story?

7. What are the most important values you hold if you would be the main hero in your fairytale story?

\section{Conclusions}

Overall, the study shows the strength of the basic imprinting and triggers, and as well a potential for symbolic transformation, in the answers rarely are presented skills or new behaviour, more selfawareness, mindfulness, values strengthening and changing to the real self. Transformational processes in organization usually are based on the symbolic imprinting and symbolic triggers, levels of learning from 2 to 4. Symbolic context in organizations provides the combination of factors initiating the change. Symbolic sphere is characterized by the tense created within the symbol's duality. Symbol is gravitating towards zero, completion, absolute beginning. Tense means fluctuations, as symbolic context in organization is an act of exchange, social relation, code simulacra. Managing symbolic processes is like regulating temperature for the thermodynamic systems to get to the bifurcation point and get to the more complex level. Chaos engenders structures only by the specific 'accidently' fitting conditions, and today the manager's main target is to predict and control these conditions to understand what chaos will lead organization to at the bifurcation point, and moreover, to utilize it for achieving specific organizational goals. Such conditions in the organization, so-called 'regulating parameters' can be symbolic triggers. 


\section{References}

Atkinson, Marilyn W. and Chois, Rae T. 2007. The Art \& Sience of Coaching, Inner Dynamics. Exalon Publishing Ltd. Bateson, Gregory. 1972. Steps to an Ecology of Mind. New York, NY: Ballantine Books.

Baudrillard, Jean. 1994. Simulacra and Simulation. Ann Arbor, MI: University of Michigan Press.

Eliade, Mircea. 1991. Images and Symbols: Studies in Religious Symbolism. Princeton, NJ: Princeton University Press.

Goldsmith, Marshall. 2015. Triggers: Creating Behavior That Lasts-Becoming the Person You Want to Be. Marshall Goldsmith, Inc.

Langer, Susan. 2000. Philosophy in a New Key. A Study in the Symbolism of Reason, Rite, and Art. Respublica, (in Russian).

Svasian, Karen. 2000. Problem of Symbol in Contemporary Philosophy. Erevan: AN ArmSSR, (in Russian). 